\title{
Berbamine induces SMMC-7721 cell apoptosis via upregulating p53, downregulating survivin expression and activating mitochondria signaling pathway
}

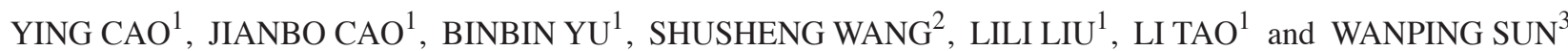 \\ Departments of ${ }^{1}$ Pharmacy and ${ }^{2}$ Surgery, Zhangjiagang Hospital Affiliated to Soochow University, \\ Zhangjiagang, Jiangsu 215600; ${ }^{3}$ Laboratory of Molecular Diagnostics, College of Pharmaceutical Sciences, \\ Soochow University, Suzhou, Jiangsu 215123, P.R. China
}

Received April 27, 2017; Accepted November 22, 2017

DOI: $10.3892 /$ etm.2017.5637

\begin{abstract}
Hepatocellular carcinoma (HCC) is a primary malignancy in the liver, which is a global health problem. The present study aimed to observe the apoptotic effects of berbamine on SMMC-7721 cell lines and to investigate the effects of berbamine on induction of the intrinsic apoptotic pathway. The human HCC SMMC-7721 cells were cultured and cell morphology observed using a phase contrast microscope. SMMC-7721 cell apoptosis was examined by employing a flow cytometry assay. The nuclei of SMMC-7721 cells were stained with DAPI and observed by utilizing a laser fluorescence microscope. Cytochrome $c$ (Cyto $c$ ) levels were evaluated by using immunofluorescence staining. The reverse transcription-semi-quantitative polymerase chain reaction (RT-sqPCR) and western blot analysis were used to examine the mRNA and protein levels of B-cell lymphoma 2, (Bcl-2), Bax, Bcl-2-associated X, apoptosis regulator, p53 and survivin, respectively. Berbamine inhibited SMMC-7721 cell growth at 20 and $0 \mu \mathrm{mol} / 1$, compared with control group ( $0 \mu \mathrm{mol} / 1$ berbamine). DAPI results demonstrated that berbamine affected the nucleus morphology of SMMC-7721 cells. Berbamine at a concentration of $20 \mu \mathrm{mol} / 1(\mathrm{P}<0.05)$ and $40 \mu \mathrm{mol} / 1(\mathrm{P}<0.01)$ significantly enhanced apoptosis rate compared with control group. Berbamine triggered Cyto $c$ release from SMMC-7721 cell nuclei to the cytoplasm. Berbamine (10, 20, $40 \mu \mathrm{mol} / \mathrm{l})$ significantly enhanced Bax and p53 levels and decreased Bcl-2 and survivin levels compared with control group, according to RT-sqPCR and western blot assay findings. In conclusion, berbamine induced SMMC-7721 cell apoptosis, through upregulating p53
\end{abstract}

Correspondence to: Dr Wanping Sun, Laboratory of Molecular Diagnostics, College of Pharmaceutical Sciences, Soochow University, 199 Renai Road, Suzhou, Jiangsu 215123, P.R. China E-mail: sunwppeeing@hainan.net

Key words: hepatocellular carcinoma, SMMC-7721, berbamine, apoptosis expression and downregulating survivin expression, which further triggered mitochondria signaling pathway-mediated apoptosis.

\section{Introduction}

Hepatocellular carcinoma (HCC) is a kind of primary malignancy in the liver, which is a global health problem, and characterizes with higher mortality and morbidity rates (1-3). The HCC is the 5th most prevalent type of cancer and the 3rd leading reason for the higher cancer-associated mortality all over the world $(2,4)$. In the worldwide, there are $\sim 650,000$ HCC cases were reported annually, in which 75-80\% distributes in the Asian countries, and 55\% distributes in China $(5,6)$. Meanwhile, in China, the HCC has become the second leading cause for the cancer-related mortality (7). Nowadays, the chemotherapetic treatment is the most common and efficacy strategy for HCC therapy, however, a series of side-effects, such as the drug resistance and the toxicity, limit the application in clinics (8). Therefore, attempting to discover a kind of effective chemotherapeutic agent is urgent and critical for the HCC therapy.

In recent years, many traditional Chinese medicine has been studied and a few of effective and safe antitumor compounds have been screened (9). Berbamine is one of the active components that extracted from the Berberis amurensis, a traditional Chinese medicine, which is a kind of alkaloid (10). The berbamine is crystallized and it's structure (molecular formula: $\mathrm{C}_{37} \mathrm{H}_{48} \mathrm{~N}_{2} \mathrm{O}_{6} \cdot 2 \mathrm{HCl}$ ) has been revealed in the past years (10). The berbamine has been applied for centuries, to treat the inflammatory diseases and the other disorders (11-21). The natural compounds and their associated derivatives of the traditional Chinese medicine are the promising candidates for the anticancer drugs $(15,16)$. Actually, a large number of the phytochemicals characterize with anticancer effects in many cancer model in both in vivo and in vitro levels (17). In recent years, many reported that the berbamine could inhibit proliferation of plenty tumors in vitro levels, including breast cancer, non-small cell lung cancer (NSCLC), multiple myeloma and the leukaemia (18-21). Especially, the berbamine could 
significantly inhibit the proliferation of the durg-resistant leukemia in vivo (22). Moreover, the berbamine could also therapy the imatinib-resistant chronic myeloid leukemia effectively according to a clinical research (23).

To the best of our knowledge, there are only a few studies $(15,24,25)$ investigating the effects of berbamine on the human HCC. Therefore, further researches are required and necessary to investigate the biological function and protective roles of berbamine in HCC. In the present study, the hepatocarcinoma cell, SMMC-7721 was used, which is a commonly used representative $\mathrm{HCC}$ cell line according to the previous studies $(6,15,16)$. The SMMC-7721 was treated in vitro with the berbamine at different concentrations. This study aims to observe the apoptotic effects of berbamine on SMMC-7721 cell lines and to investigate the effects of berbamine on induction of intrinsic apoptotic pathway.

\section{Materials and methods}

Cell culture of SMMC-7721. The human normal hepatocyte and the human HCC cell line, SMMC-7721, were purchased from the Cell Bank of Shanghai Institute of Cell Biology, Chinese Academy of Sciences (Shanghai, China). The SMMC-7721 cells were cultured in the Dulbecco's modified Eagle's medium (DMEM) containing $100 \mu \mathrm{g} / \mathrm{ml}$ streptomycin sulfate, $100 \mathrm{U} / \mathrm{ml}$ penicillin and $10 \%$ fetal bovine serum (FBS) (all from Gibco-BRL, Grand Island, NY, USA). The SMMC-7721 cells were incubated in a humidified incubator (Thermo Electron Corporation, Waltham, MA, USA) and $5 \% \mathrm{CO}_{2}$ atmosphere at $37^{\circ} \mathrm{C}$. The SMMC-7721 cells were detached from the cell plates by utilizing the $0.25 \%$ trypsin (Sigma-Aldrich; Merck KGaA, Darmstadt, Germany) for 3 min when the cells growing to near confluence.

Cytotoxicity on cells (MTT assay) and $I_{50}$. The MTT assay was employed to examine the cytotoxicity $\left(\mathrm{IC}_{50}\right)$ or the cell viability. Briefly, the normal hepatocyte and the SMMC-7721 were placed within the 96 -well culture plates at a density of $5 \times 10^{3}$ cells/well in $200 \mu \mathrm{l}$ medium at $37^{\circ} \mathrm{C}$ for $24 \mathrm{~h}$. Total of $20 \mu \mathrm{l}$ of MTT solution $(5 \mathrm{mg} / \mathrm{ml}$; Sigma-Aldrich; Merck KGaA) was added to the 96-well plates, and cultured for $4 \mathrm{~h}$. Then, the supernatant was discarded and the DMSO was added (150 $\mu \mathrm{l} /$ well; Sigma-Aldrich; Merck KGaA). The absorbance was measured by using a Universal microplate reader (SpectraMax Plus 384; Molecular Devices, LLC, Sunnyvale, CA, USA) at the wavelength of $570 \mathrm{~nm}$. The cytotoxicity of normal hepatocyte of SMMC-7721 cells was illustrated as $\mathrm{IC}_{50}$ (concentration of $50 \%$ cytotoxicity, which was extrapolated form the linear regression analysis of experimental findings).

Cell morphology observation. The SMMC-7721 cells were added to the DMEM medium and the cell concentration was adjusted to $1 \times 10^{5}$ cells $/ \mathrm{ml}$, and the cell were seeded into the 6 -wells plate $(2 \mathrm{ml} /$ well). The cells were cultured for $24 \mathrm{~h}$, and then treated with the different concentration of crystallized berbamine $(10,20$ and $40 \mu \mathrm{mol} / 1$, cat. no. 6078-17-7; Shanghai Standard Technology Co., Ltd., Shanghai, China) for another $24 \mathrm{~h}$. The berbamine at the concentration of $0 \mu \mathrm{mol} / \mathrm{l}$ was considered as control group (without berbamine treatment, and only with DMEM). The cell morphology was observed and photographed by employing the phase contrast microscope.

Apoptosis examination. SMMC-7721 cells apoptosis was examined by employing FITC-Annexin V/PI cell apoptosis kit (cat. no. C1062; Beyotime Biological Technology Co., Ltd., Shanghai, China) due to the manufacturer's instructions. The SMMC-7721 cells were harvested by utilizing $0.25 \%$ trypsin, and rinsed the PBS for three times, then cells were suspended in the $500 \mu \mathrm{l}$ binding buffer. The suspended SMMC-7721 cells were treated with Annexin V-FITC $(5 \mu \mathrm{l})$ at $4^{\circ} \mathrm{C}$ for $10 \mathrm{~min}$. Then, SMMC-7721 cells were treated with 7-ADD solution (10 $\mu \mathrm{l}$ ) at $4^{\circ} \mathrm{C}$ for $5 \mathrm{~min}$. Finally, SMMC-7721 cell apoptosis was evaluated by using FACS flow cytometer (BD Biosciences Inc., Franklin Lakes, NJ, USA).

DAPI staining. The cover glasses were embedded into the 6-well plates, and the SMMC-7721 cells were added for culturing $4 \mathrm{~h}$. Then, the different concentrations of berbamine $(0,10,20$ and $40 \mu \mathrm{mol} / \mathrm{l})$ were added into the culture medium. Total of $48 \mathrm{~h}$ later, the SMMC-7721 cells were fixed with the 4\% paraformaldehyde for $15 \mathrm{~min}$ and subsequently incubated with the LysoTracker (red) at $37^{\circ} \mathrm{C}$ for $30 \mathrm{~min}$. The cells were then washed by using the PBS for 3 times, and the nuclei were counter-stained by using the 4'-6-diamidino-2-phenylindole (DAPI; Roche Diagnostics, Basel, Switzerland). The fluorescent images were observed by utilizing a laser fluorescence microscope (Olympus, Tokyo, Japan).

Immunofluorescence staining for cytochrome c (Cyto c). The treatment for cells were performed according to the processes of 'DAPI staining' section. After the PBS washing, the SMMC-7721 cells were incubated by using the 5\% BSA (Gibco-BRL) for $0.5 \mathrm{~h}$, and washed with PBS for 3 times. Then, the cells were incubated with the rabbit anti-human Cyto $c$ monoclonal antibody (cat. no. ab133504, 1:1,000; Abcam, Cambridge, MA, USA) at room temperature for $2 \mathrm{~h}$. Then, the cells were washed with the PBS for 3 times, and 5 min per time. The cells were incubated with the FITC-conjugated goat anti-rabbit IgG (cat. no. ab6717, 1:2,000; Abcam) at room temperature for $1 \mathrm{~h}$ in dark. Finally, the cells were re-stained by using the DAPI for $10 \mathrm{~min}$, and mounting. The fluorescent images were observed by using a fluorescence microscope (Olympus).

Reverse transcription-semi-quantitative polymerase chain reaction ( $R T$-sqPCR). Total cellular RNAs were extracted by utilizing RNAsimple Total RNA kit (Sigma-Aldrich; Merck KGaA). Then, the First-Strand cDNA Synthesis kit (Invitrogen Life Technologies, Carlsbad, CA, USA) was used to synthesize cDNA due to manufacturer's instructions. Then, the synthesized cDNA was used to amplify the target genes by utilizing PCR assay under the following conditions: $95^{\circ} \mathrm{C}$ for $4 \mathrm{~min}$, following with 30 cycles of $94^{\circ} \mathrm{C}$ for $30 \mathrm{sec}, 55^{\circ} \mathrm{C}$ for $30 \mathrm{sec}, 72^{\circ} \mathrm{C}$ for $30 \mathrm{sec}$, and terminated with $72^{\circ} \mathrm{C}$ for $10 \mathrm{~min}$. The primers for Bcl-2, Bax, p53, survivin and GAPDH (synthesized by Western Biotechnology Inc., Chongqing, China) were listed in Table I. Finally, the amplified products were loaded onto $1.5 \%$ agarose gels, and the images were digitally captured 
Table I. Sequence of the primers used for reverse transcription-semi-quantitative polymerase chain reaction.

\begin{tabular}{lc}
\hline Genes & \multicolumn{1}{c}{ Sequence (5'-3') } \\
\hline Bax & \\
Forward & \\
Reverse & GCTCTGAGCAGATCATGAAG \\
Bcl-2 & CAAAGTAGAAAAGGGCGACA \\
Forward & \\
Reverse & CCGGGAGATAGTGATGAAGT \\
p53 & ACTCAAAGAAGGCCACAATC \\
Forward & \\
Reverse & ACATGTGTAACAGTTCCTGC \\
Survivin & TCCATCCAGTGGTTTCTTCT \\
Forward & \\
Reverse & CCAGTGTTTCTTCTGCTTCA \\
GAPDH & CGCACTTTCTTCACAGTTTC \\
Forward & \\
Reverse & AAGATCATCAGCAATGCCTC \\
\hline
\end{tabular}

Bcl-2, B-cell lymphoma-2; Bax, Bcl-2 associated X, apoptosis regulator.

by using the camera and analyzed with the image analysis software.

Western blot analysis. The SMMC-7721 cells were lysed with the lysis buffer. The lysis products were separated by using the 15\% SDS-PAGE and the total proteins in the gels were electro-transferred onto PVDF membranes (Amersham Biosciences, Piscataway, NJ, USA). The membranes were blocked with the $5 \%$ defatted milk in the PBS supplementing with $0.05 \%$ Tween- 20 at $4^{\circ} \mathrm{C}$ for $1 \mathrm{~h}$. The membranes were incubated with the rabbit anti-human Bcl-2 monoclonal antibody (cat. no. ab31124, 1:3,000) and mouse anti-human Bax monoclonal antibody (cat. no. ab77566, 1:3,000), rabbit anti-human survivin polyclonal antibody (cat. no. ab469, 1:2,000) (all from Abcam), mouse anti-human p53 monoclonal antibody (cat. no. 554167, 1:3,000; BD Biosciences Inc.) and rabbit anti-human GAPDH polyclonal antibody (cat. no. ab9385, 1:2,000; Abcam) at $4^{\circ} \mathrm{C}$ overnight. Then, the membranes were incubated with the horseradish peroxidase (HRP)-conjugated goat anti-rabbit (cat. no. ab6721, 1:2,000) and HRP-conjugated goat anti-mouse (cat. no. ab6789, 1:2,000) (both from Abcam) at room temperature for $1.5 \mathrm{~h}$. The western blot bands were visualized by using the TMB color liquid (PE Applied Biosystems, Foster City, CA, USA).

Statistical analysis. The data were analyzed by using the SPSS 19.0 software (SPSS Inc., Chicago, IL, USA). The data were illustrated as the mean \pm standard deviation. The comparisons among multiple groups were analyzed by using the ANOVA test followed by the Tukey's post host test. The comparisons between two groups were analyzed by using the Student's t-test. P-value $<0.05$ was considered to indicate a statistically significant difference.
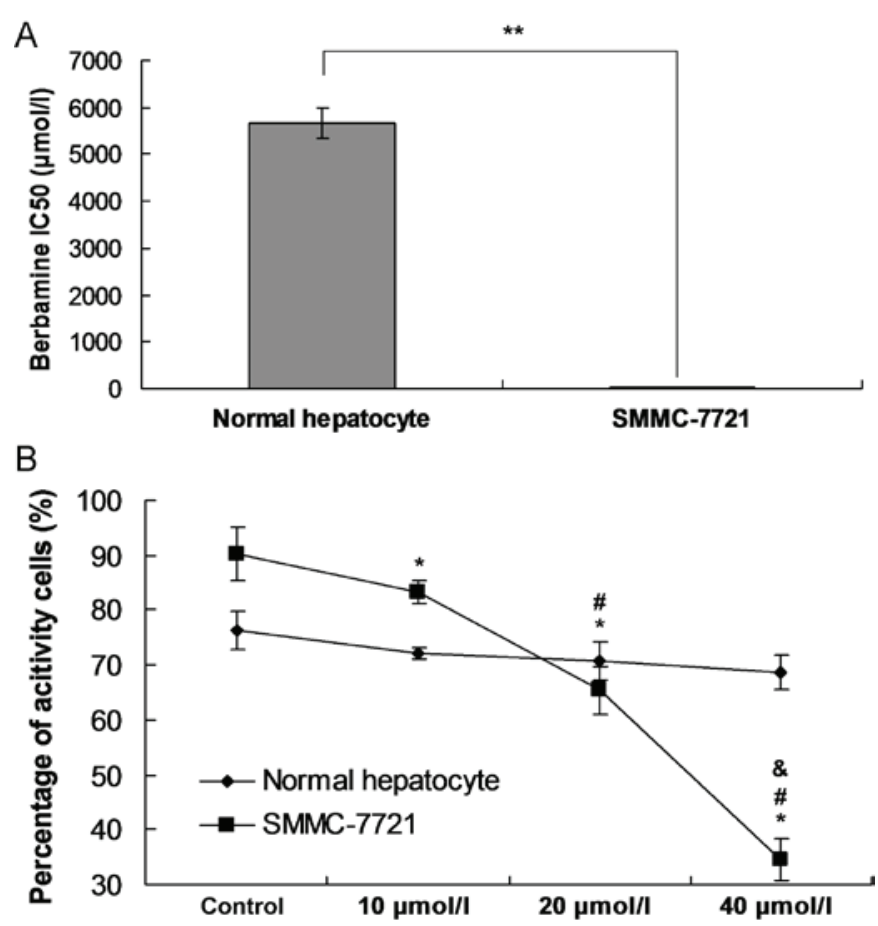

Figure 1. Observation for the $\mathrm{IC}_{50}$ and cell viability. (A) $\mathrm{IC}_{50}$ examination ${ }^{* *} \mathrm{P}<0.05$ represents the $\mathrm{IC}_{50}$ in $\mathrm{SMMC}-7721$ group compared to normal hepatocyte group. (B) Cell viability was examined by using MTT assay. ${ }^{*} \mathrm{P}<0.05$ represents the cell viability compared to control group. ${ }^{*} \mathrm{P}<0.05$ represents the cell viability compared to $10 \mu \mathrm{mol} / 1$ berbamine. ${ }^{\&} \mathrm{P}<0.05$ represents the cell viability compared to $20 \mu \mathrm{mol} / 1$ berbamine.

\section{Results}

Berbamine exhibits no significant cytotoxic potential to normal hepatocyte. In order to confirm the cytotoxic potential of berbamine to the normal hepatocyte, the $\mathrm{IC}_{50}$ was examined, and the MTT assay was also performed in this study. The results indicated that the $\mathrm{IC}_{50}$ value in normal hepatocyte group $(5670.94 \mu \mathrm{mol} / \mathrm{l})$ was higher significantly compared to the SMMC-7721 group $(35.48 \mu \mathrm{mol} / \mathrm{l})$ (Fig. $1 \mathrm{~A} ; \mathrm{P}<0.001)$. The MTT assay also showed that the there were even not cytotoxic effects of berbamine on the cell viability of normal hepatocyte at different concentrations (Fig. 1B). However, the cell viability of SMMC-7721 group was significantly decreased following with the increased concentration of berbamine (Fig. 1B; all $\mathrm{P}<0.05)$.

Berbamine inhibits SMMC-7721 cells growth. According to the cell morphology, the SMMC-7721 cells in control group grew well, and formed the fusion colony cells (Fig. 2A). However, following the increased concentration of berbamine (from 10 to $40 \mu \mathrm{mol} / \mathrm{l}$ ), the SMMC-7721 cell amounts were obviously decreased (Fig. 2B-D). Meanwhile, the SMMC-7721 cells in Control group were pleomorphic, and SMMC-7721 cells in other group were round or elliptical (Fig. 2). Moreover, some of the cells also suspended in the medium in 20 and $40 \mu \mathrm{mol} / 1$ berbamine group. These results suggest that the berbamine obviously inhibited the SMMC-7721 cells growth.

Berbamine affects nucleus morphology. The SMMC-7721 cells were stained with DAPI and observed under the 

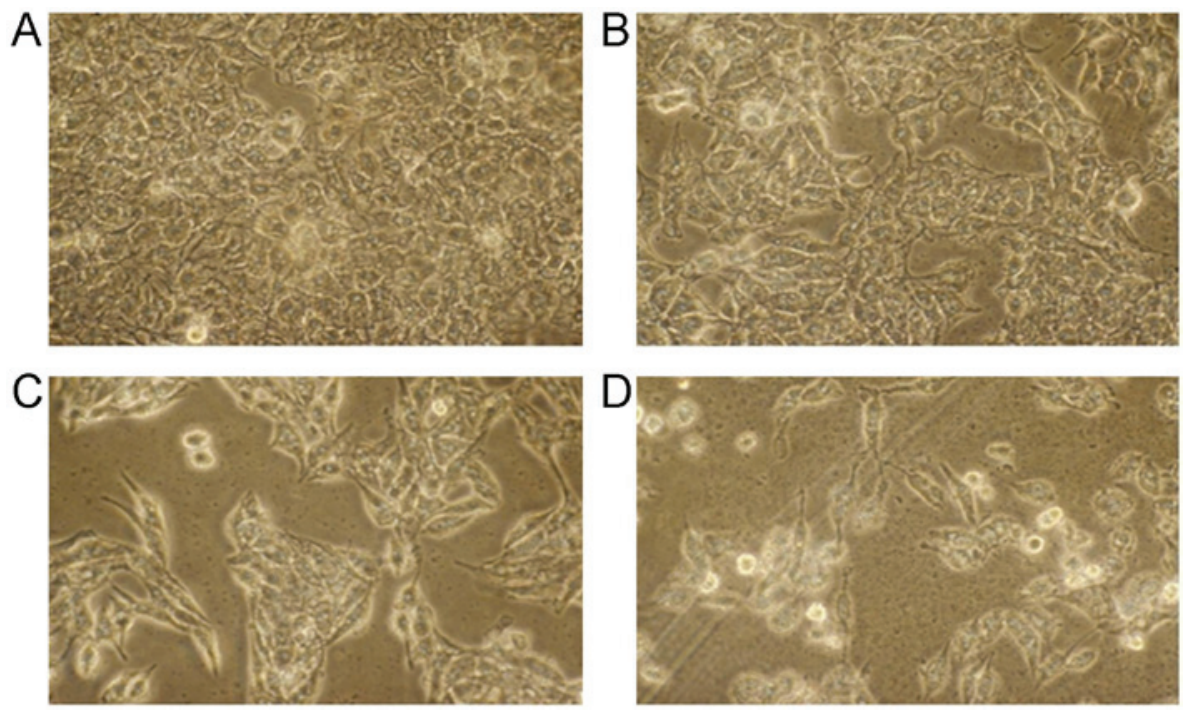

Figure 2. Cell morphology observation for SMMC-7721 cells under inverted microscope (magnification, x200). (A) Control group; (B) $10 \mu \mathrm{mol} / 1$ berbamine; (C) $20 \mu \mathrm{mol} / 1$ berbamine; and (D) $40 \mu \mathrm{mol} / 1$ berbamine.
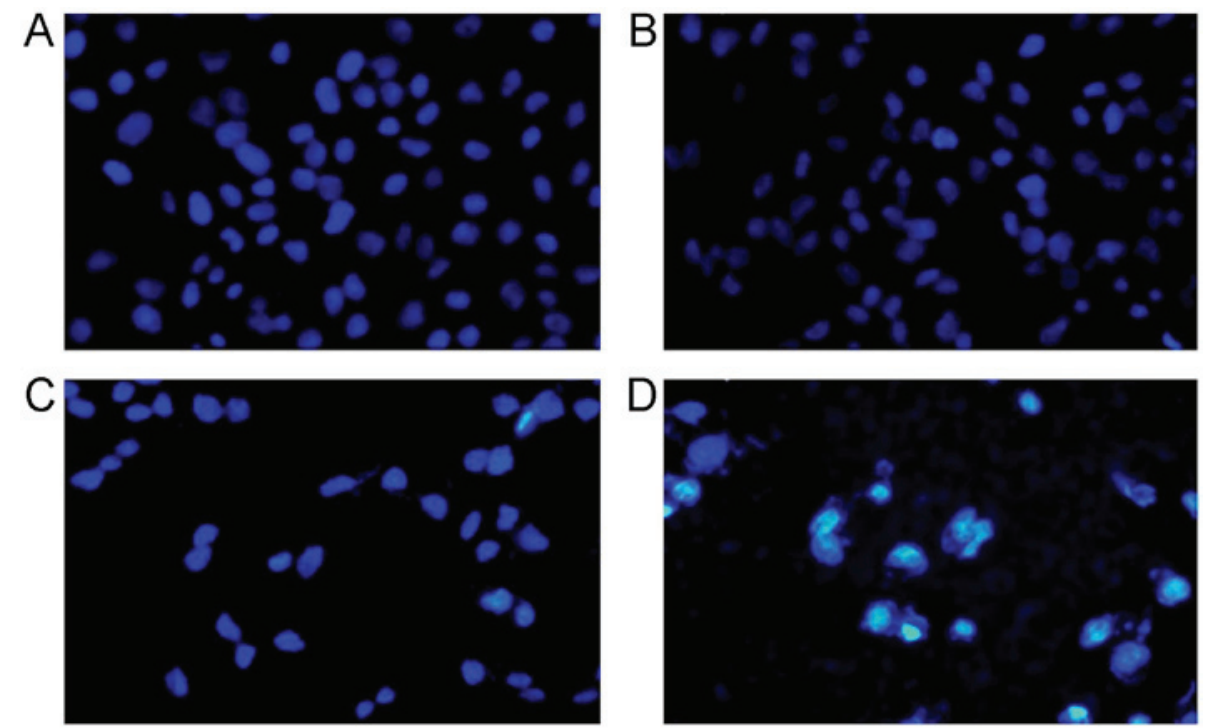

Figure 3. DAPI staining for SMMC-7721 cell nucleus observed under immunofluorescence microscope (magnification, x200). (A) Control group; (B) $10 \mu \mathrm{mol} / 1$ berbamine; (C) $20 \mu \mathrm{mol} / 1$ berbamine; (D) $40 \mu \mathrm{mol} / 1$ berbamine. The light stained cells represent the DAPI positively stained cells.

microscope. The results indicated that the cells illustrated the normal cell morphology and the nucleus were round and stained homogeneously in control group (Fig. 3A). The nucleus were narrowed and deeply stained $48 \mathrm{~h}$ post the $10 \mu \mathrm{mol} / 1$ berbamine treatment (Fig. 3B). In $20 \mu \mathrm{mol} / \mathrm{l}$ berbamine treatment group, we found the deeply stained nucleus, chromatin condensation in most SMMC-7721 cells (Fig. 3C). However, the nucleus illustrated as strong fluorescence staining, fragmentary and polymorphonuclear in $40 \mu \mathrm{mol} / 1$ berbamine treatment (Fig. 3D). The nucleus in Fig. 3B-D illustrated the classical apoptotic morphology.

Berbamine induces SMMC-7721 cells apoptosis. Forty-eight hours post the berbamine treatment, the SMMC-7721 cells were stained with the Annexin V/PI. The results indicated that the berbamine $(10 \mu \mathrm{mol} / \mathrm{l})$ increased the apoptosis rate, however, no significant difference was discovered compared to Control group (Fig. 4A and B, $\mathrm{P}>0.05$ ). The berbamine at concentration of $20 \mu \mathrm{mol} / 1(\mathrm{P}<0.05)$ and $40 \mu \mathrm{mol} / 1(\mathrm{P}<0.01)$ significantly enhanced the apoptosis rate compared to the Control group, respectively (Fig. 4A, C and D).

Berbamine triggers Cyto c release from SMMC-7721 nucleus. The immunofluorescence staining was used to examine the Cyto $c$ release from the SMMC-7721 nucleus. The results indicated that the Cyto $c$ was slightly stained in the control group (Fig. 5), and which mainly distributed in the nucleus. However, the staining of Cyto $c$ in berbamine treatment was significantly strengthened in 20 and $40 \mu \mathrm{mol} / 1$ compared to control group (Fig. 5), and the Cyto $c$ was transferred from the nucleus to the cytoplasm.

Berbamine enhances Bax and p53 levels and decreases Bcl-2 and survivin levels. In this study, four apoptosis associated 


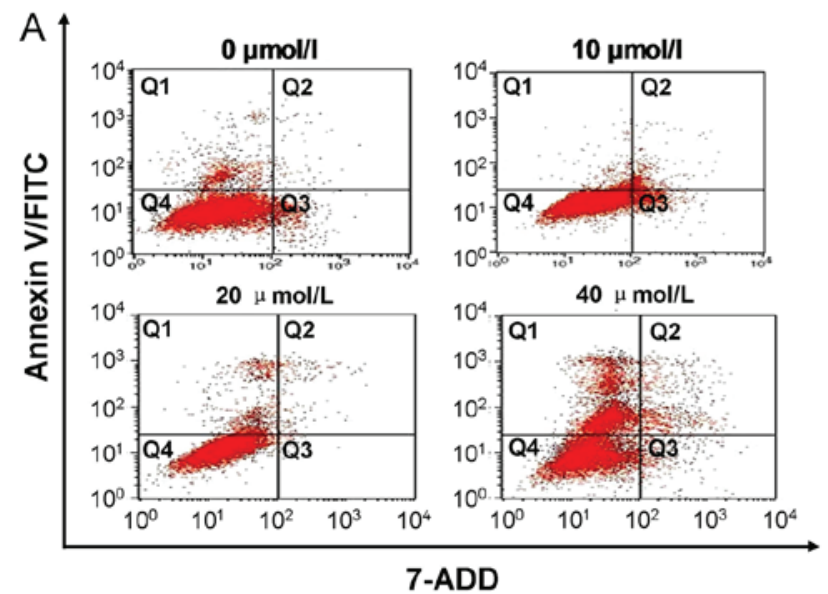

B

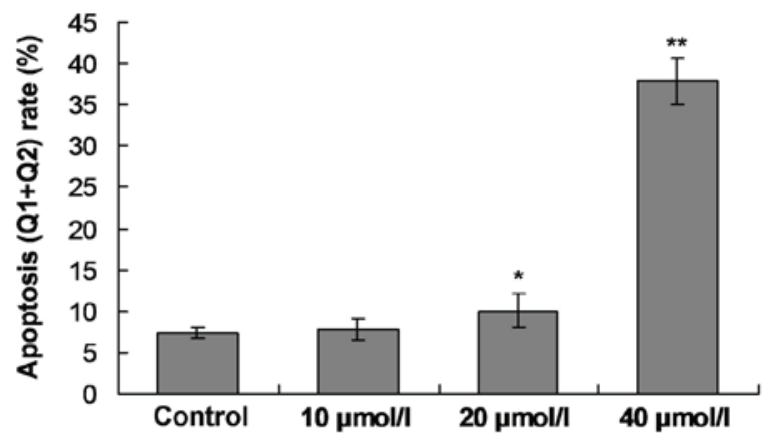

Figure 4. Observation for the Berbamine induced SMMC-7721 cell apoptosis by using flow cytometry assay. (A) Images for flow cytometry assay in every groups. (B) Statistical analysis for flow cytometry assay. Q1 quadrant represents the living cells; Q2 quadrant represents the early apoptosis cells; Q3 quadrant represents the late apoptosis cells; and Q4 quadrant represents the death cells. The apoptosis rate was composed of percentage of Q1 plus Q2. " $\mathrm{P}<0.05$ and ${ }^{* *} \mathrm{P}<0.01$ represent apoptosis rate compared to the control group.

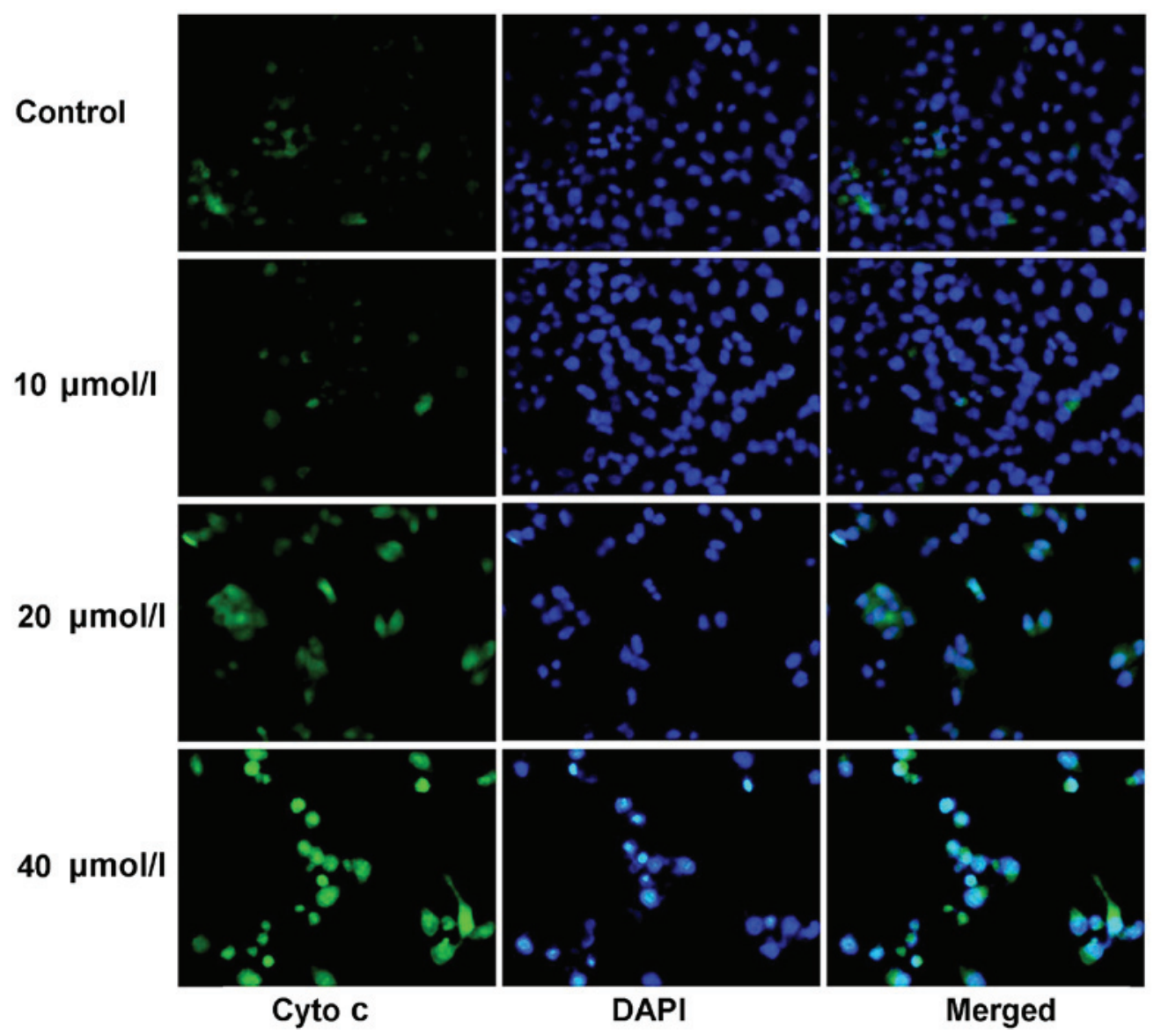

Figure 5. Examination for the Cyto $\mathrm{C}$ expression by using immunofluorescence assay at $48 \mathrm{~h}$ post berbamine treatment (magnification, $\mathrm{x} 200$ ). The green fluorescence illustrates Cyto $\mathrm{C}$ staining, the blue fluorescence illustrates DAPI staining, the merged images are the Ctyo C and DAPI double stained SMMC-7721 cells.

biomarkers, including Bax, Bcl-2, p53 and survivin, were examined by using both of RT-sqPCR and western blot analysis. The RT-sqPCR results showed that the Bax and p53 mRNA levels were significantly increased in 10, 20 and $40 \mu \mathrm{mol} / 1$ berbamine treatment group compared to control group (Fig. 6; $\mathrm{P}<0.05$ ). Meanwhile, the $\mathrm{Bcl}-2$ and survivin
mRNA levels were significantly decreased in 10, 20 and $40 \mu \mathrm{mol} / 1$ berbamine treatment group compared to control group (Fig. 6; $\mathrm{P}<0.05$ ).

Moreover, the western blot assay also showed that the Bax and p53 protein levels were significantly increased, and Bcl-2 and survivin protein levels were significantly decreased in 10 , 
A

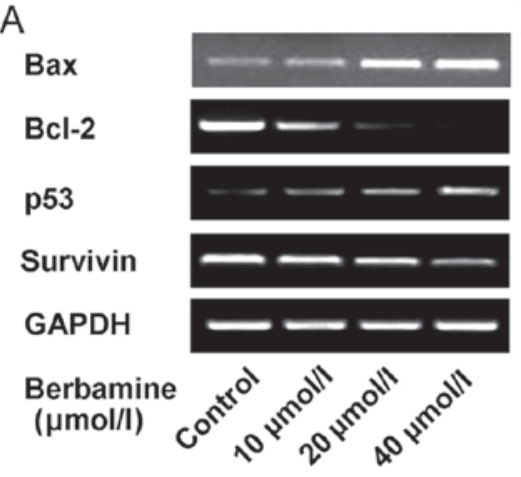

B

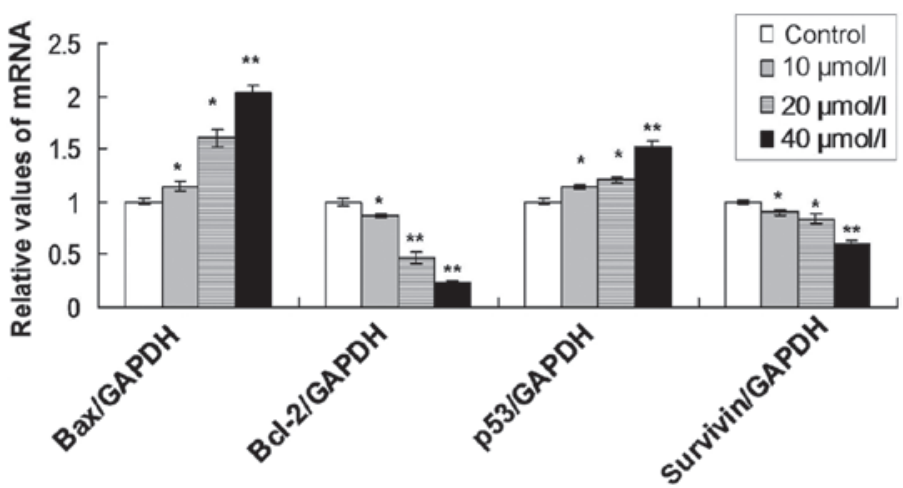

Figure 6. RT-sqPCR examination for the apoptosis associated genes in berbamine treated SMMC-7721 cells. (A) RT-sqPCR bands for the Bax, Bcl-2, p53 and survivin mRNA expression. (B) Statistical analysis for the mRNA expression. ${ }^{*} \mathrm{P}<0.05$ and ${ }^{* *} \mathrm{P}<0.01$ represent the mRNA expression compared to the control group. The data are presented as the mean \pm standard deviation $(n=6)$.

A

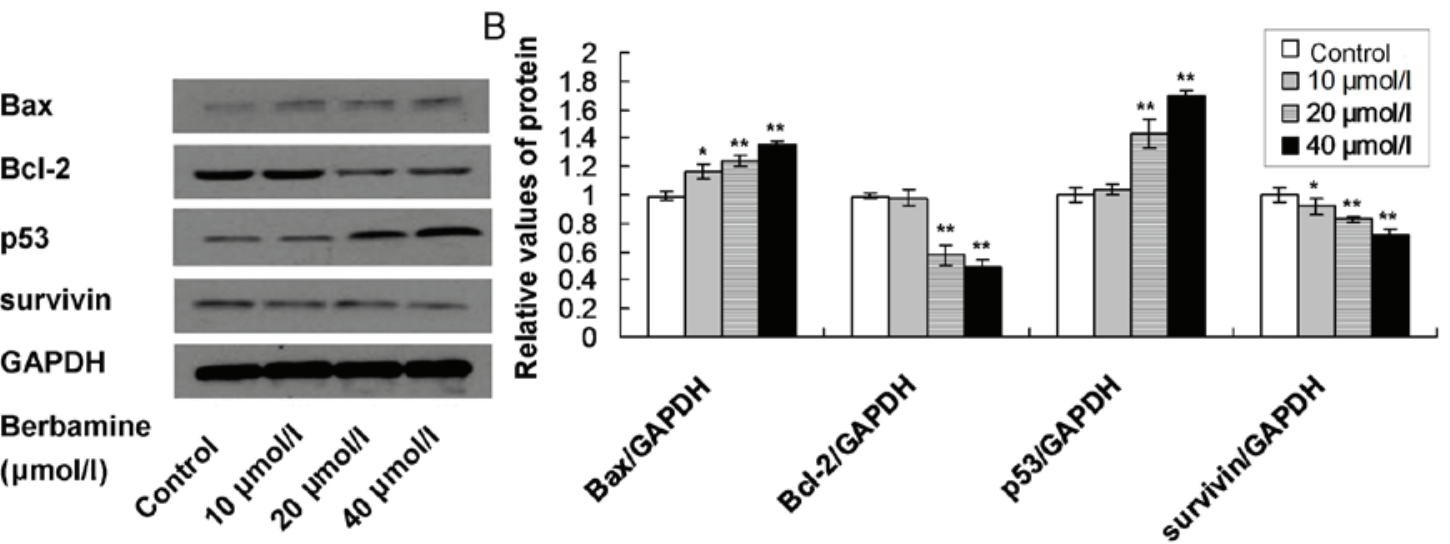

Figure 7. Western blot analysis examination for apoptosis associated proteins in berbamine treated SMMC-7721 cells. (A) Western blot bands for Bax, Bcl-2, p53 and survivin protein expression. (B) Statistical analysis for the protein expression. ${ }^{*} \mathrm{P}<0.05$ and ${ }^{* *} \mathrm{P}<0.01$ represent the protein expression compared to the control group. The data are presented as the mean \pm standard deviation $(n=6)$.

20 and $40 \mu \mathrm{mol} / 1$ berbamine treatment group compared to control group (Fig. 7; $\mathrm{P}<0.05$ ).

\section{Discussion}

Although the berbamine has been extensively applied for many cancer treatment, however, the anticancer role of berbamine in HCC therapy has not been fully investigated. In this study, we studied the anticancer effects of berbamine on the SMMC-7721 cells proliferation and apoptosis.

Anti-apoptosis is the typical characteristic for the cancer cells, therefore, induction of cancer cell apoptosis is a key end for developing antitumor drugs (26). Therefore, this study observed the nucleus morphology of the SMMC-7721 cells, and the nucleus illustrated as fragmentary and polymorphonuclear in 20,40 $\mu \mathrm{mol} / 1$ berbamine treatment, which suggests that the classical apoptotic morphology was appeared in the berbamine treatment cells. Meanwhile, the apoptosis rate was also evaluated by using the flow cytometry assay, and results revealed that berbamine at concentration of 20 and $40 \mu \mathrm{mol} / 1$ significantly induced apoptosis compared to the control group, which suggests that berbamine processes the function of anti-apoptosis in SMMC-7721 cells, and is consistent with previous study $(19,27)$.
The cell apoptosis mainly includes endogenous apoptosis and exogenous apoptosis, and the mitochondira-associated apoptosis is the key process for endogenous apoptosis. For the mitochondria-associated apoptosis, the Cyto $c$ transferred from the nuclues to mitochondria and cytoplasm, and the Bcl-2 protein family plays an important role in the whole apoptotic processes (28). Our result indicated that Cyto $c$ levels in berbamine treatment was significantly increased in 20 and $40 \mu \mathrm{mol} / 1$ compared to control group, which suggest that the Cyto $c$ was transferred from the nucleus to the cytoplasm and mitochondria, and induced the apoptosis. Among the Bcl-2 family proteins, the Bcl-2 belongs to the anti-apoptotic protein and Bax belongs to the pro-apoptotic protein (29), both of which regulate the activity of the caspase protein and induce the cascade cell apoptosis (30). In our study, berbamine significantly enhanced Bax levels and decreased Bcl-2 levels compared to the un-treated with berbamine group, which suggests that the apoptosis of SMMC-7721 was triggered by the mitochondria-associated signaling pathway.

p53 is the most common antitumor gene of $20 \mathrm{~kb}$, which includes 11 exons and 10 introns, and participates in the processes of cell cycle regulation, DNA damage repair and induction of apoptosis $(28,31)$. Normally, the p53 remains the low levels, however, when DNA damaged p53 was 
overexpressed, which upregulated pro-apoptotic genes, downregulated anti-apoptotic genes through multiple-signaling pathways (32). In our study, the p53 expression was significantly increased in berbamine treatment group compared to no berbamine treatment group. The over-expressed p53 may trigger the increased expression of Bax and decreased expression of Bcl-2 in SMMC-7721 cells. Survivin is a recent years discovered anti-apoptotic protein, which participates in the progression and development of malignant tumors (33). The survivin inhibits the cell apoptosis by inhibiting apoptotic factors, caspase- 3 and -7 activity directly (34). The present results indicated that berbamine significantly inhibited the survivin mRNA and protein expression in SMMC-7721 cells. The above results suggest that the p53 and survivin play critical role in berbamine triggered apoptosis.

Recent years, there were many studies based on berbamine derivatives have been published. Nam et al (35) reported that the berbamine derivatives could inhibit the Jak2/Stat3 signaling and induce apoptosis of human melanoma cells. $\mathrm{Xu}$ et al (36) showed that the berbamine derivatives affect the $\mathrm{Ca}^{2+}$-stimulated $\mathrm{Mg}^{2+}$-dependent ATPase in erythrocyte membranes. Liang et al (37) reported that 4-chlorbenzoyl berbamine as a novel derivative of berbamine, could inhibit the growth of human myeloma cells by modulating the NF- $\mathrm{\kappa B}$ and JNK signaling pathway. Meanwhile, a few previously published studies $(15,24,25)$ also reported the berbamine induced SMMC-7721 cell apoptosis in the other signaling pathways. Wang et al $(24,25)$ proved that the berbamine induced apoptosis was mediated by the mitochondrial transmembrane potential and Fas-mediated mediated signaling pathway. Meng et al (15) also found that the berbamine induced the apoptosis and inhibited tumor growth by activating $\mathrm{Ca}^{2+} /$ calmodulin-dependent protein kinase II. In the present study, berbamine induced SMMC-7721 cells apoptosis through upregulating p53 expression and downregulating survivin expression, which is distinguish from the above studies $(15,24,25)$.

However, the specific pathways that mediated the role of berbamine have not been fully clarified. Therefore, we thought that the mechanism for the anticancer effects of berbamine in HCC cell lines may also involve many other signaling pathways. In the further studies, we would attempt to investigate the mechanism of action of berberine further by examining the crosstalk between different signaling pathways, such as the p53-dependent signaling pathway, MAPK-survivin signaling pathway and PI3K-Akt pathway.

Totally, the present findings fully proved that the berbamine exhibited higher anticancer activity and trigger-proliferation activity, by activating p53 and survivin expression and triggering the mitochondria signaling pathway. We speculated that interfering the $\mathrm{p} 53$ and survivin may control the progression of the HCC. Meanwhile, the extraction process of the berbamine is simple and the price is low. Therefore, the we believed that the present results are significant for clinics.

Although this study received some interesting results, there were also a few limitations. Firstly, the cancer-specific effects of berbamine on the cancer progression has not been fully explored. Secondarily, we have not compared the compound of berbamine to the standard of care, may be there have been a synergistic effect. Thirdly, the extrinsic apoptotic pathway proteins, such as caspase- 8 and -10 , were not examined. Fourthly, the commercially available p53 and survivin inhibitors were not employed to confirm the effect of berbamine on the intrinsic apoptosis signaling pathway in the present study. Fifthly, although the total levels of Cyto $c$ was examined, the Cyto $c$ transfer from nucleus to cytoplasm has not been observed.

In conclusion, berbamine induced SMMC-7721 cells apoptosis, through upregulating p53 expression and downregulating survivin expression, which further triggers mitochondria signaling pathway mediated apoptosis. In the following researches, we would investigate the molecular mechanisms for berbamine triggered antitumor activity, and evaluate it's security.

\section{Acknowledgements}

This study was granted by Suzhou People's Livelihood Science and Technology Projects (grant no. SYSD2015151).

\section{References}

1. Parkin DM, Bray F, Ferlay J and Pisani P: Global cancer statistics, 2002. CA Cancer J Clin 55: 74-108, 2005.

2. Chun JM, Kwon HJ, Sohn J, Kim SG, Park JY, Bae HI, Yun YK and Hwang YJ: Prognostic factors after early recurrence in patients who underwent curative resection for hepatocellular carcinoma. J Surg Oncol 103: 148-151, 2011.

3. Zhang SL and Liu L: microRNA-148a inhibits hepatocellular carcinoma cell invasion by targeting sphingosine-1-phosphate receptor 1. Exp Ther Med 9: 579-584, 2015.

4. Jemal A, Siegel R, Ward E, Hao Y, Xu J and Thun MJ: Cancer statistics, 2009. CA Cancer J Clin 59: 225-249, 2009.

5. Asia-Pacific Working Party on Prevention of Hepatocellular Carcinoma: Prevention of hepatocellular carcinoma in the Asia-Pacific region: Consensus statements. J Gastroenterol Hepatol 25: 657-663, 2010.

6. Yuen MF, Hou JL and Chutaputti A; Asia Pacific Working Party on Prevention of Hepatocellular Carcinoma: Hepatocellular carcinoma in the Asia pacific region. J Gastroenterol Hepatol 24: 346-353, 2009.

7. Han LL, Lv Y, Guo H, Ruan ZP and Nan KJ: Implications of biomarkers in human hepatocellular carcinoma pathogenesis and therapy. World J Gastroenterol 20: 10249-10261, 2014.

8. Hernandez-Gea V, Turon F, Berzigotti A and Villanueva A: Management of small hepatocellular carcinoma in cirrhosis: Focus on portal hypertension. World J Gastroenterol 19: 1193-1199, 2013.

9. Luo KW, Sun JG, Chan JY, Yang L, Wu SH, Fung KP and Liu FY: Anticancer effects of imperatorin isolated from Angelica dahurica: Induction of apoptosis in HepG2 cells through both death-receptor- and mitochondria-mediated pathways. Chemotherapy 57: 449-459, 2011.

10. Tan W, Zhou J and Yuan G: Electrospray ionization mass spectrometry probing of binding affinity of berbamine, a flexible cyclic alkaloid from traditional Chinese medicine, with G-quadruplex DNA. Rapid Commun Mass Spectrom 28: 143-147, 2014.

11. Goto M: A comparative study of anti-inflammatory and antidyslipidemic effects of fenofibrate and statins on rheumatoid arthritis. Mod Rheumatol 20: 238-243, 2010.

12. Nam S, Xie J, Perkins A, Ma Y, Yang F, Wu J, Wang Y, Xu RZ, Huang W, Horne DA and Jove R: Novel synthetic derivatives of the natural product berbamine inhibit Jak2/Stat3 signaling and induce apoptosis of human melanoma cells. Mol Oncol 6: 484-493, 2012.

13. Wang S, Liu Q, Zhang Y, Liu K, Yu P, Luan J, Duan H, Lu Z, Wang F, Wu E, et al: Suppression of growth, migration and invasion of highly-metastatic human breast cancer cells by berbamine and its molecular mechanisms of action. Mol Cancer 8: 81, 2009.

14. Gu Y, Chen T, Meng Z, Gan Y, Xu X, Lou G, Li H, Gan X, Zhou H, Tang J, et al: CaMKII $\gamma$, a critical regulator of CML stem/progenitor cells, is a target of the natural product berbamine. Blood 120: 4829-4839, 2012. 
15. Meng Z, Li T, Ma X, Wang X, Van Ness C, Gan Y, Zhou H, Tang J, Lou G, Wang Y, et al: Berbamine inhibits the growth of liver cancer cells and cancer-initiating cells by targeting $\mathrm{Ca}^{2+} /$ calmodulin-dependent protein kinase II. Mol Cancer Ther 12: 2067-2077, 2013.

16. Ding X, Zhu FS, Li M and Gao SG: Induction of apoptosis in human hepatoma SMMC-7721 cells by solamargine from Solanum nigrum L. J Ethnopharmacol 139: 599-604, 2012.

17. Nishino H, Satomi Y, Tokuda H and Masuda M: Cancer control by phytochemicals. Curr Pharm Des 13: 3394-3399, 2007.

18. Dai XH, Liu R, Zhou Y, Yang M, Fan DM, Xiong DS, Qi J, Yang CZ and Zhu HF: Effect of calmodulin antagonist O-4-ethoxyl-butyl-berbamine on the proliferation of human breast cancer cell line MCF-7 and its relevant mechanism. Zhongguo Yi Xue Ke Xue Yuan Xue Bao 31: 326-329, 2009 (In Chinese).

19. Jin $X$ and $\mathrm{Wu} Y$ : Berbamine enhances the antineoplastic activity of gemcitabine in pancreatic cancer cells by activating transforming growth factor- $\beta /$ Smad signaling. Anat Rec (Hoboken) 297: 802-809, 2014.

20. Hou ZB, Lu KJ, Wu XL, Chen C, Huang XE and Yin HT: In vitro and in vivo antitumor evaluation of berbamine for lung cancer treatment. Asian Pac J Cancer Prev 15: 1767-1769, 2014.

21. Xie J, Ma T, Gu Y, Zhang X, Qiu X, Zhang L, Xu R and Yu Y: Berbamine derivatives: A novel class of compounds for anti-leukemia activity. Eur J Med Chem 44: 3293-3298, 2009.

22. Wei YL, Xu L, Liang Y, Xu XH and Zhao XY: Berbamine exhibits potent antitumor effects on imatinib-resistant CML cells in vitro and in vivo. Acta Pharmacol Sin 30: 451-457, 2009.

23. Zhao Y, Tan Y, Wu G, Liu L, Wang Y, Luo Y, Shi J and Huang H: Berbamine overcomes imatinib-induced neutropenia and permits cytogenetic responses in Chinese patients with chronic-phase chronic myeloid leukemia. Int J Hematol 94: 156-162, 2011.

24. Wang GY, Zhang JW, Lü QH, Xu RZ and Dong QH: Berbamine induces apoptosis in human hepatoma cell line SMMC7721 by loss in mitochondrial transmembrane potential and caspase activation. J Zhejiang Univ Sci B 8: 248-255, 2007.

25. Wang GY, Lv QH, Dong Q, Xu RZ and Dong QH: Berbamine induces Fas-mediated apoptosis in human hepatocellular carcinoma HepG2 cells and inhibits its tumor growth in nude mice. J Asian Nat Prod Res 11: 219-228, 2009.

26. Dao P, Jarray R, Smith N, Lepelletier Y, Le Coq J, Lietha D, Hadj-Slimane R, Herbeuval JP, Garbay C, Raynaud F and Chen $\mathrm{H}$ : Inhibition of both focal adhesion kinase and fibroblast growth factor receptor 2 pathways induces anti-tumor and anti-angiogenic activities. Cancer Lett 348: 88-99, 2014.
27. Yang F, Nam S, Brown CE, Zhao R, Starr R, Ma Y, Xie J, Horne DA, Malkas LH, Jove R and Hickey RJ: A novel berbamine derivative inhibits cell viability and induces apoptosis in cancer stem-like cells of human glioblastoma, via up-regulation of miRNA-4284 and JNK/AP-1 signaling. PLoS One 9: e94443, 2014.

28. Goldar S, Khaniani MS, Derakhshan SM and Baradaran B: Molecular mechanisms of apoptosis and roles in cancer development and treatment. Asian Pac J Cancer Prev 16: 2129-2144, 2015.

29. Diao SL, Xu HP, Zhang B, Ma BX and Liu XL: Associations of MMP-2, BAX, and Bcl-2 mRNA and protein expressions with development of atrial fibrillation. Med Sci Monit 22: 1497-1507, 2016.

30. Besbes S, Mirshahi M, Pocard M and Billard C: New dimension in therapeutic targeting of BCL-2 family proteins. Oncotarget 6 : 12862-12871, 2015.

31. Dang YP, Yuan XY, Tian R, Li DG and Liu W: Curcumin improves the paclitaxel-induced apoptosis of HPV-positive human cervical cancer cells via the NF- $\kappa \mathrm{B}-\mathrm{p} 53$-caspase-3 pathway. Exp Ther Med 9: 1470-1476, 2015.

32. Wu C, Zhang J, Cao X, Yang Q and Xia D: Effect of mir-122 on human cholangiocarcinoma proliferation, invasion, and apoptosis through P53 expression. Med Sci Monit 22: 2685-2690, 2016.

33. Altieri DC: Survivin - The inconvenient IAP. Semin Cell Dev Biol 39: 91-96, 2015.

34. Wang Y, Ma W and Zheng W: Deguelin, a novel anti-tumorigenic agent targeting apoptosis, cell cycle arrest and anti-angiogenesis for cancer chemoprevention. Mol Clin Oncol 1: 215-219, 2013.

35. Nam S, Xie J, Perkins A, Ma Y, Yang F, Wu J, Wang Y, Xu RZ, Huang W, Home DA and Jove R: Novel synthetic derivatives of the natural product berbamine inhibit Jak/Stat3 signaling and induce apoptosis of human melanoma cells. Mol Oncol 6: 484-493, 2012

36. Xu YH, Liu J, Zhang SP and Liu LH: The effect of berbamine derivatives on $\mathrm{Ca}^{2+}$-stimulated $\mathrm{Mg}^{2+}$-dependent ATPase in erythrocyte membranes. Biochem J 248: 985-988, 1987.

37. Liang Y, He X, Li X, Zhang X, Zhang X, Zhang L, Qiu X, Zhao $X$ and Xu R: 4-Chlorbenzoyl berbamine, a novel derivative of the natural product berbamine, potently inhibits the growth of human myeloma cells by modulating the NF- $\kappa \mathrm{B}$ and JNK signalling pathways. Cancer Invest 34: 496-505, 2016.

This work is licensed under a Creative Commons Attribution-NonCommercial-NoDerivatives 4.0 International (CC BY-NC-ND 4.0) License. 